\title{
Service Learning to Increase Utilization of X Video Editing Software Features within Limited Facilities for the Youth of Gereja Kristen Pasundan Cideres
}

\author{
Pin Panji Yapinus ${ }^{1 *}$ \\ ${ }^{1}$ Bachelor Program in Computer Engineering, Faculty of Engineering \\ Universitas Kristen Maranatha, Bandung, Indonesia \\ pin.py@eng.maranatha.edu \\ Leon Karsten ${ }^{2}$, Emmanuel F. Sigit Bayu P. ${ }^{3}$, Gilberth Giandy Taruna Kesumah ${ }^{4}$, \\ Rudianov Z.A. Parera ${ }^{5}$, Richard Anderson ${ }^{6}$ \\ ${ }^{2}$ Bachelor Program in Computer Engineering, Faculty of Engineering \\ Universitas Kristen Maranatha, Bandung, Indonesia \\ 3,4,5,6 Directorate of Student and Alumni Affairs \\ Universitas Kristen Maranatha, Bandung, Indonesia \\ Leon.karsten028@gmail.com,Emmanuelfebianosigit@gmail.com, \\ it1773001@student.it.maranatha.edu, rudianov.p@maranatha.edu, fransiskusanderson@gmail.com
}

(Received February 05, 2021, accepted May 25, 2021)

\begin{abstract}
The service learning in multimedia skills for teenagers and young people as training program for the community was conducted through the expertise of Bachelor Program in Computer Engineering, Faculty of Engineering, Universitas Kristen Maranatha, for Gereja Kristen Pasundan (GKP) Cideres. The purpose of this training was to equip people with skills or knowledge that can be useful in daily activities. As this training was given during the Covid19 pandemic, by requirement of health and safety protocols, the service learning was implemented online via the internet in a form of webinar. Online digital activities are increasingly important as conventional physical interactions and communication in work or study environment become unsafe and to be avoided or to be done less often than usual. Unfortunately for most people, technical skills for working or studying online are not yet adequate, especially in multimedia using some recent tools and softwares. So in this program, basic multimedia producing skills using Microsoft Photos (video editing feature) and Microsoft Power Point were introduced. The end result of the training was satisfactory, as those who participate are being able to produce simple digital multimedia presentation using the aforementioned tools and softwares. The training program was held online on November 28th, 2020 via Zoom Meeting Application, and was made possible thanks to the collaboration of Bachelor Program in Computer Engineering with the Directorate of Student and Alumni Affairs, Universitas Kristen Maranatha.
\end{abstract}

Keywords: Covid-19 pandemic; multimedia; service learning 
Service Learning to Increase Utilization of X Video Editing Software Features within Limited Facilities for the Youth of 122 Gereja Kristen Pasundan Cideres

\section{Introduction}

Gereja Kristen Pasundan (GKP) Cideres located in Dusun Cideres, Cipaku village, District of Kadipaten, Majalengka Regency, Province of West Java, Indonesia. For daily activities related to church affairs, GKP Cideres is usually assisted by the younger generation of church members. There are quite a lot of activities that require expertise in processing video and multimedia, especially during the Covid-19 pandemic which has been going on since the end of 2019 until now. For example, religious activities such as Sunday services need to be held online, where congregants attend services from their own homes, while pastors guide congregations from the church using a computer connected via the internet. It is also often necessary to provide reports, information and announcements of church activities using video. Audio visual communication with the use of video become a necessity.

The GKP Cideres management sees that to provide support for the smooth implementation of church activities, GKP youth still need to improve their skills in processing video and multimedia using computers. In addition, because the average GKP Cideres youth are in the school age range, such as college students and high school students, this ability to process video and multimedia can also support learning activities in schools which during the pandemic were also carried out online remotely. Many school assignments need to be done through video presentations.

Church youth actually already have a little ability to produce videos. They use an application that officially can be downloaded for free on their respective cell phones (smartphones). This application is called KineMaster. Some have tried using a free downloadable software called Filmora, software that can run on personal computer laptops. The results obtained using this application and software are still not in accordance with the needs of the church, since these softwares were limited in features because the nature of the free product.

The church youth have been trying to find other software alternatives in producing videos. Some of the findings are in the form of professional software which is quite expensive and requires considerable computer system performance. Church officials and church youth generally have insufficient computer or laptop capabilities to run these kind of softwares. 
Service Learning to Increase Utilization of X Video Editing Software Features within Limited Facilities for the Youth of 123 Gereja Kristen Pasundan Cideres

GKP Cideres has a good relationship with one of the staff in the Directorate of Student and Alumni Affairs at Universitas Kristen Maranatha. Through the staff, the problems experienced by the church were conveyed to the expert team at Bachelor Program in Computer Engineering, Universitas Kristen Maranatha to find solutions. To get a solution to the problems experienced by the GKP Cideres, the Directorate of Student and Alumni Affairs together with the Bachelor Program in Computer Engineering Universitas Kristen Maranatha made some observations.

From initial observations, the Bachelor Program in Computer Engineering Universitas Kristen Maranatha is sure to provide solutions according to their expertise, from choosing what software suits the needs of processing video and multimedia at GKP Cideres to providing short training session for the youth at GKP Cideres to use the software. The activity would be carried out in a form of service learning. Service learning is education based on collaboration of experienced speaker, college students, and participants from the society (Ansori et al., 2021). This method create a conducive atmosphere in exploring needs, establishing learning materials, and participative training.

Videos and movies can be categorized as one of mass media in conveying messages to society (Atas, 2019). Basic multimedia skills are perceived to be important nowadays, since they are practically benefit those who needs to communicate and to interact with others to carry on their jobs or for study purposes. Multimedia is the use of computers to present and combine text, sound, images, animation, audio and video with (tools) and connections (links) so that users can navigate, interact, create and communicate (Sahren et al., 2020). Most modern organizational environment require these skills especially during long pandemic occurance. This encouraged GKP Cideres to equip the youths with such skills and asked Universitas Kristen Maranatha to help providing the training program. Media literacy according to the National Leadership Conference on Media Education is the ability to access, evaluate, and communicate messages in various forms (Megawati et al., 2019).

Hopefully that this community service would increase the participants' insights and abilities in processing multimedia videos. Producing videos does not always have to use software that is expensive and requires high computer system capabilities. Video processing is divided into three main parts, namely taking pictures (taking), perfecting the video (editing), and 
Service Learning to Increase Utilization of X Video Editing Software Features within Limited Facilities for the Youth of 124 Gereja Kristen Pasundan Cideres

combining the entire video (mixing). This activity is complemented by a training session. So that it is expected to increase the experience of participants in producing multimedia videos.

\section{Methods}

There were three stages of initial observation in this community service. The first stage was direct observation in the GKP Cideres church environment. The second stage was online virtual face-to-face discussions with church administrators. The third stage was online virtual face-to-face discussions with church youth. After these three stages were carried out, the expert from the Bachelor Program in Computer Engineering, Universitas Kristen Maranatha (in this case the lecturer) together with the student prepared training materials according to the needs of the church. In the end, the training was carried out in accordance with the input needs obtained from the observation and discussions, then finding out the training results in the form of an evaluation of the results of the activity and a month after the activity was carried out.

The second stage was carried out by conducting virtual face-to-face online meetings with church administrators. This activity is carried out using the Zoom application so that meetings during this pandemic can be carried out with more participants. At this meeting the church administrators met with lecturer from Bachelor Program in Computer Engineering, Universitas Kristen Maranatha discussed problems, requirements, and about limited facilities or equipment in the church environment related to the need to process multimedia and video.

The third stage was carried out by conducting online virtual face-to-face meetings with church youth. This activity is carried out using the Zoom application by involving the management as the owner of the facility and the church youth as the main participants of the training. At this meeting, the youth conveyed their needs in processing videos for the needs of the church and their study obligations. Lecturer records the ownership of the laptop, the operating system used, and the ownership of the software that would be used in the training. The result was that all participants used a laptop with the Windows 10 operating system and had official Microsoft Power Point and Microsoft Photos available in it. These softwares are commonly available and have some degree of video editing capability. 
From the initial observation, can be elaborated two main points below. Youth of GKP Cideres need multimedia and video editing skills upgrade which can be provided for:

1. Supporting worship activities GKP Cideres.

During the pandemic, Youth of GKP Cideres need video editing skills to show online worship on Youtube, as well as producing the church announcement. 10 out of 14 youth already used to using KineMaster, smartphone android software. But since this software runs in smartphones, the capabilities of this software in terms of usability are very limited.

2. Support the youth in completing their school assignments or homework.

At the same situation (pandemic), learning activities changes. All youth are still studying from junior high school to college. 8 out of 14 youth collect assignments in the form of a video, almost every week. So lecturer sure this training can be usefull for the Youth of GKP Cideres.

This training is specially arranged for the youth of GKP Cideres (in Figure 1). Because of almost all activities at the church performed by the youth. They need to expand the skill for the better result and the optimal performance between trainees and device especially on video editing for multimedia skill.

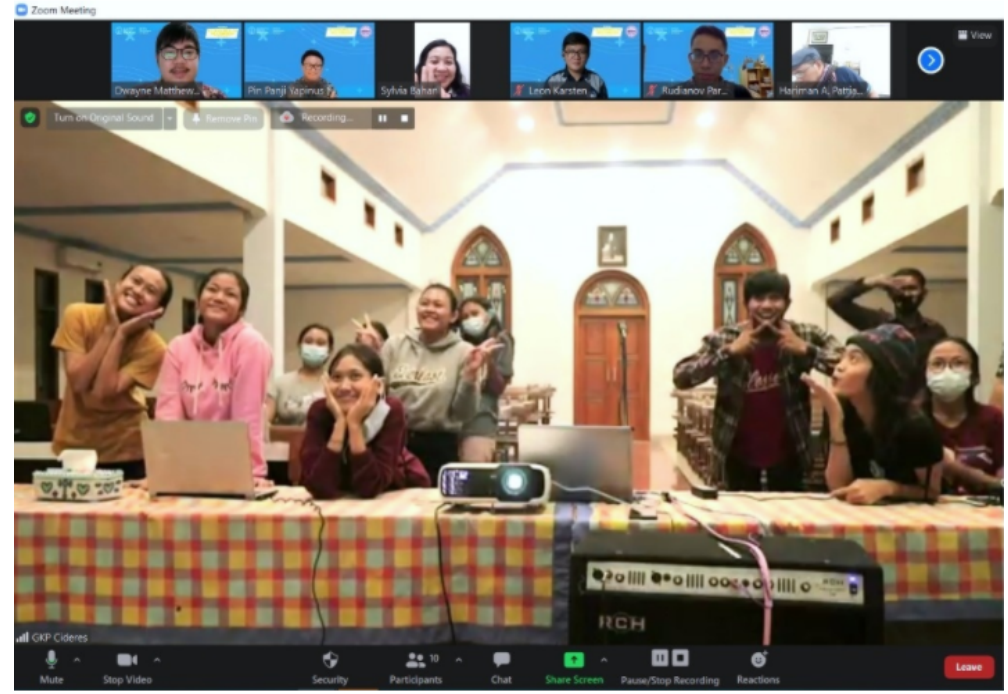

Fig. 1. Trainees from GKP Cideres

From the initial observation, there also found about conditions would be faced during the training. The conditions were:

1. Majority laptops that used by participants have limited hardware performance. In improving video editing capabilities of the GKP Cideres youth, there were limitation, 
especially on the devices they use. Usually the device used for video editing, must have strong specifications on processor, RAM, and graphics card. Based on simple survey, laptops used for video editing mostly have a low specification. (Processors on par with the first generation of Intel Core series, RAM under 2GB, MS Windows 10 operating system). As a comparison, Adobe Premiere as one of two software which used for video mixing at Movie Authoring class at the Bachelor Program in Computer Engineering requires a multicore 64 Bit processor, RAM 8 to $16 \mathrm{~GB}$, and graphics card on par with nVidia GeForce GTX 1050 (Adobe Inc, 2013).

2. Remote activities during a pandemic

Another condition faced was the Covid-19 pandemic which forced the training session to be conducted remotely by the tutor via internet. This kind of video editing training usually need to be conducted on site in physical class because the interactions between the tutor and the trainee mean a lot. Many things that can be done and can be explained thoroughly if this activity is carried out on site. Such as explaining the frame in the editing function in Microsoft Power Point as an example.

\section{Description and activities arrangements}

In the preparatory collaboration activities before the training session, the following were carried out; the assignment for the Bachelor Program in Computer Engineering personnel is to prepare training materials, then for the Directorate of Student and Alumni Affairs to prepare personnel for presenters, Zoom application operators, event note takers and documentation officers. This simple coordination was expected to keep activities running smoothly. Training activities were carried out in a virtual face-to-face using a paid Zoom application belongs to the Directorate of Student and Alumni Affairs.

The training material was based on commonly used softwares that still has the same video editing capabilities required and was chosen by considering the role of editing and mixing in the basic theory of video editing. Microsoft Power Point which is a very widely used software for audio visual presentations, often available through a Microsoft account which is usually provided through schools that have collaborated with Microsoft for use of Microsoft Office software packages for students can be used for Editing Part. Microsoft Photos which is the default software available when Microsoft Windows 10 is installed on a computer can be used for mixing the multimedia part. So that both of these softwares are relatively easy to obtain officially without spending too much extra cost. 
The training activity (in Figure 2) was also have practice session to ensure the experience of the trainees in using the software. Objects, example files, pictures, video clips, materials and everything needed for practice distributed through Google Drive. Before the activity started, participants were asked to download the exercise material.

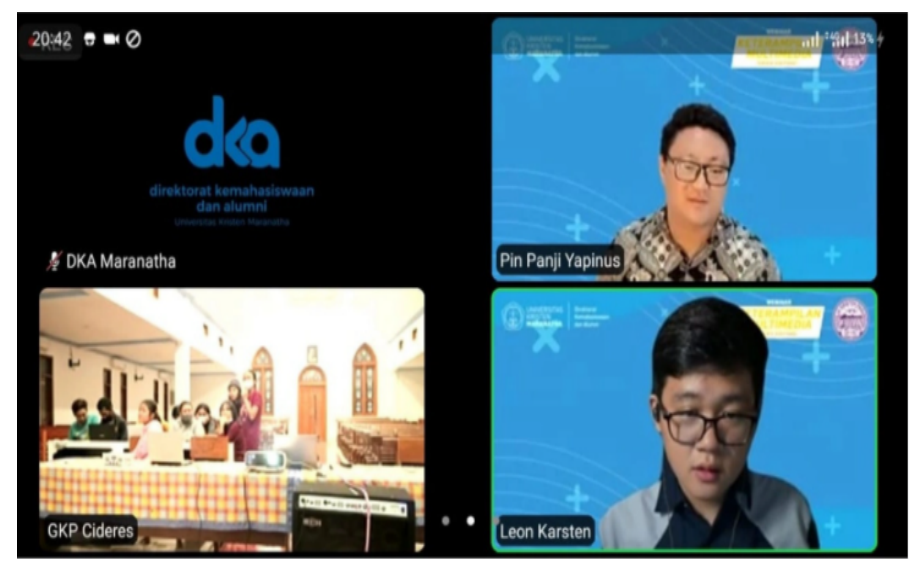

Fig. 2. Ongoing training activities

The complete steps used in this training session can be elaborated as such:

1. Initial Survey

This initial survey aimed to measure the understanding of the training participants before the training begins.

2. Short tutorial

Presentation by the tutor explaining basic idea and steps in using tools and softwares required to produce simple multimedia video

\section{Exercise}

Followed by a short exercise by the target participants in using the tools and softwares required until each participant can generate his/her multimedia video

4. Tips and suggestions

Then the tutor gave tips and suggestions about the multimedia editing along with a little introduction into working field of video editing as a closing.

5. Evaluation

During the training activity, the tutor made a simple evaluation of the work progress of the training participants. The results were collected as data about the progress of the training participants. 
The training session was also showed how to optimize the software those generally used for presentations, to convert presentation it yields into a video format. Then the video editing feature of the Microsoft Photos application can be used quite effectively to edit and process video.

The practice session after the presentation was intended to give participants the opportunity to practice hands on experience. In the session, the tutor and his assistant had prepared the arranged slides and videos to be combined into the columns on the slides provided. This was done beforehand to anticipate the limited space for activities and limited time for practice session. Practice materials such as example slides and video clips were distributed before the actual training sessions began via a link to Google Drive account, so that the participants were able to access the practice materials comfortably and have had the necessary materials for practice.

The training program was ended with the tutor giving a few conclusions, tips and suggestions, information on software recommendations for video editing and its advantages, and some motivation for the participants to keep practising as to grasp the opportunity in working field of video editing in the future. This closing session was also expected to foster participants' interest and enthusiasm in dealing with usual works, tasks, and other GKP church affairs which require video making, as a start to exercise the participants multimedia skills.

\section{Data collection from the training program activities}

The participants involved in this training activity were 19 persons of GKP Cideres. Consisting of $58 \%$ women and $42 \%$ men. 5 of them are companions or providers, 14 of them were young people participating as the trainees. So in other words, the number of participants or youth who attended this activity reached $73.68 \%$. The composition is depicted in the Figure 3.

Distinguished from the simple survey data that was collected, all the participants had done video editing with different types of software. Starting from applications found on smartphones (KineMaster) to laptop (Filmora). Before training, participants used the software on their smartphones. Based on a simple survey, 11 out of 14 participants used the software KineMaster for video editing. This software usage data is reflected in Figure 4. 


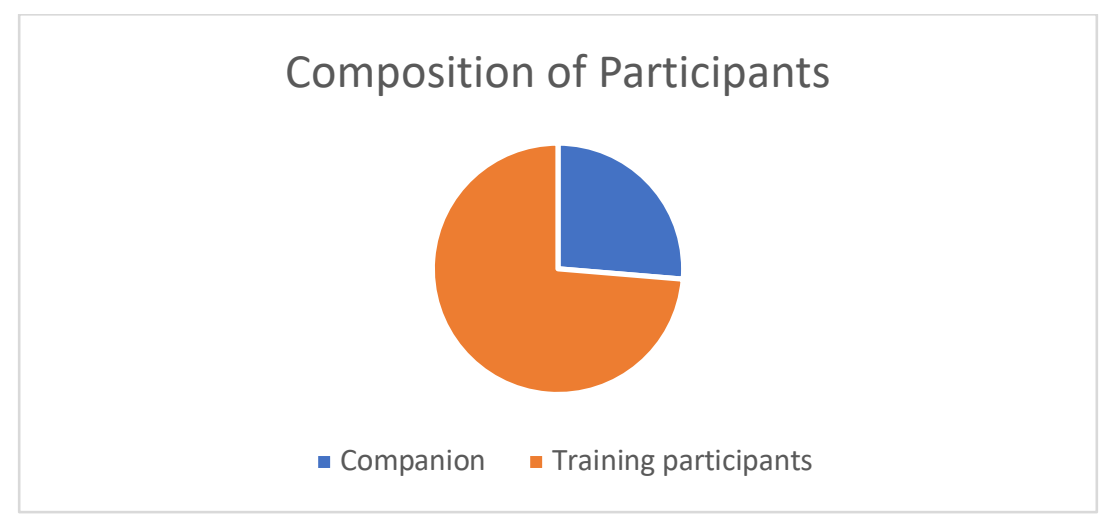

Fig. 3. Composition of participants and companion from GKP Cideres

\section{Doing Video Editing using the Mobile} Application KineMaster

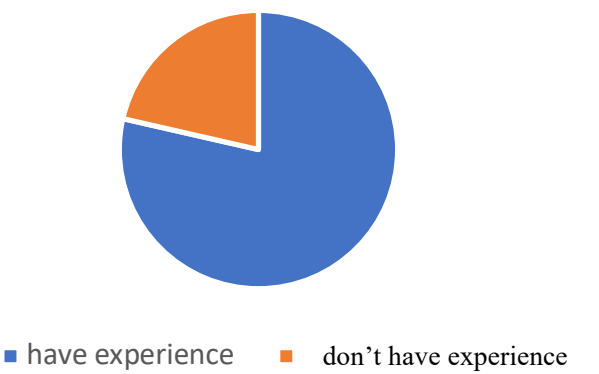

Fig. 4. Training Participants who use video editing software KineMaster

A survey was also conducted to measure participants' understanding in video editing. This time the Filmora software on laptop devices. Based on previous observations, several church members have used Filmora, but it did not continue to be used because the watermark feature on the Filmora software (because of the free software variant) was too disturbing or hampering to the final video produced. From the data obtained, 2 out of 14 participants have used the Filmora software. This condition reflected on Figure 5.

Creating a video content can be categorized into 3 main parts. Video taking (taking), changing/enhancing videos (editing), and combining videos (mixing). In this training activity the insights given to the participants were emphasized on changing/refining videos and combining videos. 


\section{Video Editing Experience using Filmora}

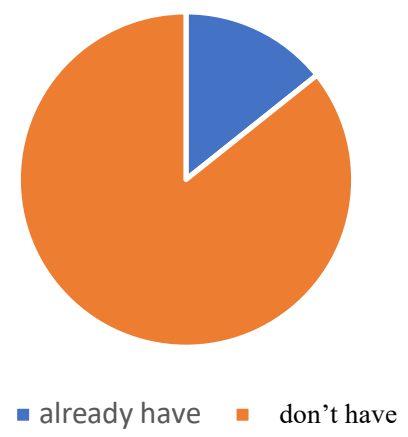

Fig. 5. Training Participants who already have video editing experience using Filmora

A simple survey was carried out to measure the understanding of the training participants in professional video editing (Such as Adobe products). However, none of the participants had ever used professional software to edit videos. Participants feel that their devices have limited capabilities and also the cost of such software are too expensive. On the other hand, the training participants have never and do not know the features of making videos using Microsoft Power Point and Microsoft Photos software. Nonetheless, participants already have the software installed on their own laptops.

Based on the data gathered, all participants have done some sort of video editing before the training. Video editing was mostly performed to fulfill the individual school assignments and some presentation work by request from the GKP Cideres (church affairs). Training participants used to utilize standard smartphones applications, because they are easy to use, have adequate features for practical daily use, and are considered not sufficient for making video of assignments and usual activities at the GKP Cideres. Specialized softwares such as Filmora, Adobe Premiere and Adobe After Effects, were not become their choice since these kind of softwares though specified as a complete solution for video editing, they also requires fairly high computer performance specifications, hence costly to operate, especially the Adobe Premiere and Adobe After Effects.

\section{Data collection at the end of the training activities}

The training activities were carried out successfully by all participants. Participants were successful in using Microsoft Power Point and video files that were distributed through Google Drive. But each participants got different results. This is due to the use of devices 
with different capabilities. Another thing that affects this is probably minimal direct supervision during activities. The success data is shown in Figure 6.

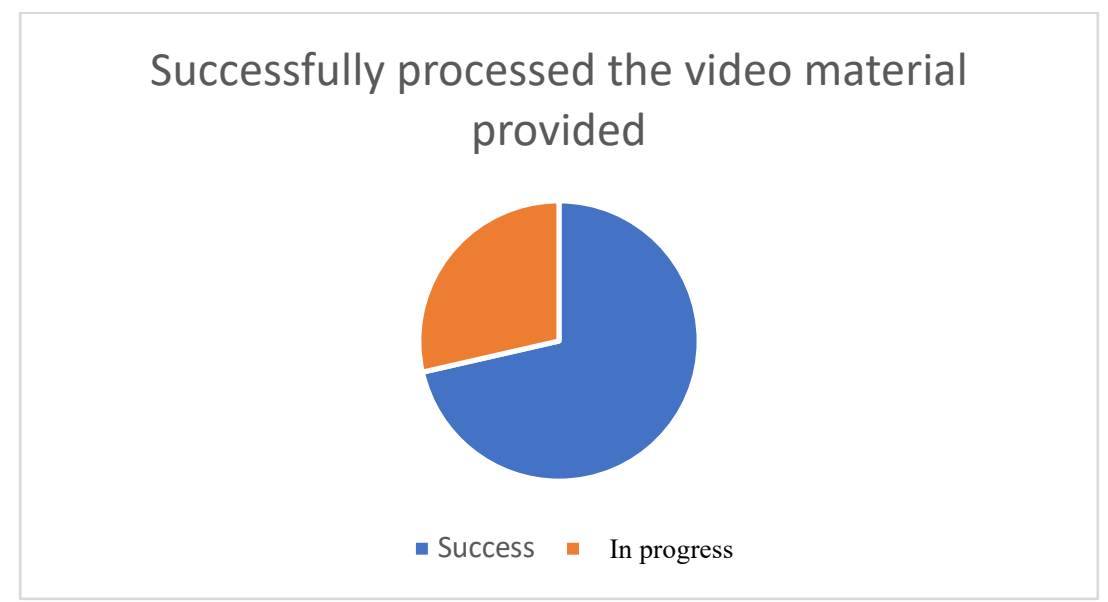

Fig 6. Training participants who successfully processed the video material provided

Based on the results of online observations and surveys, 10 participants claimed to have successfully processed the video on the Microsoft Power Point that had been provided. In this case, the success rate of the video processing method on Microsoft Power Point reached $71.43 \%$.

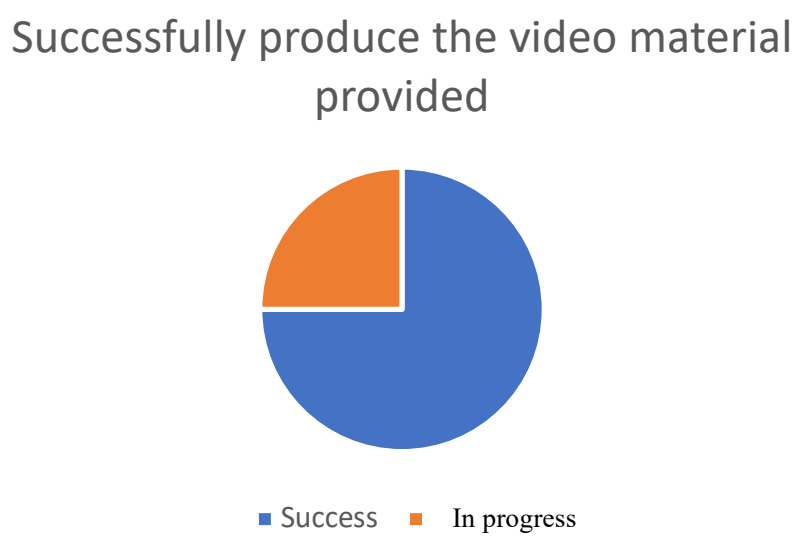

Fig. 7. Training participants who successfully produced the video material provided

Based on the results of online observations and surveys, 3 out of 10 participants claimed to have successfully processed the video on common presentation software, were able to produce final video material. In this case, the success rate of participants in producing videos reached $30 \%$. This is due to the different capabilities of participant's laptops and the selection of the desired video quality results (Ultra High Definition, Full High Definition, High Definition, and Standard). From this survey it is reflected that the level of supervision in 
video editing is also important. So that if there are questions or errors, they can be directly handled by the assistant on duty. The survey is shown in the Figure 7.

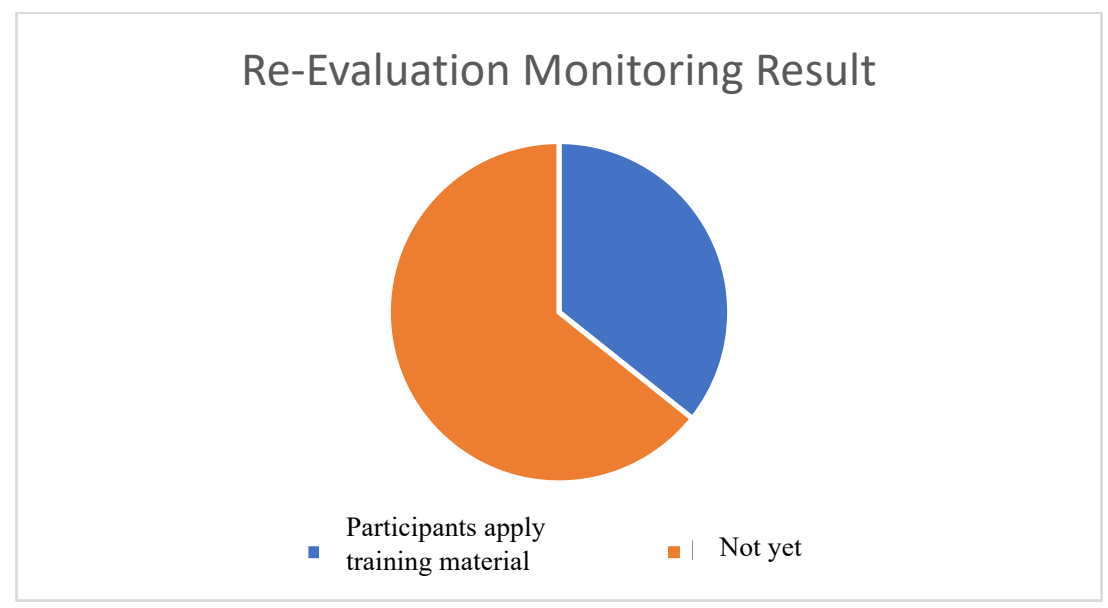

Fig. 8. Re-evaluation monitoring result

After 3 months have passed, a re-evaluation was carried out to monitor the effectivity of the training provided. There are 5 out of 14 participants stated that they believe the training provided has help them to better utilize the common available presentation and video editing softwares to successfully carry on their church and daily school assignments. The effectivity of the training session provided is perceived to reach $35.71 \%$. But this low effectivity rate was probably because of the fact that not all training participant assigned to work on video processing yet since the training. The re-evaluation result is shown in the Figure 8.

\section{Results and Discussions}

The community service learning through training to improve youth video and multimedia skills at GKP Cideres was successfully carried out. This material was utilizing the common available presentation and video editing softwares for multimedia processing. The use of these two softwares is intended so that the needs of GKP Cideres youth in video processing can be developed by utilizing the existing software in the midst of the conditions they are experiencing without extra cost.

Microsoft Power Point has always been a software that supports users of the windows operating system. Mostly this software used just for presentation. This software has features to edit videos, that rarely people know or used it. Actually it can be a solution for low performance laptop of the participants to support multimedia processing. Windows 10 
operating system provide built-in application that can be used for support video editing. The application is Photos, which can be used to edit photos and also videos in simple and easy way. Because this application is built-in software, users do not need to make extra installation and no extra cost, so it can be considered for daily use.

To meet the needs and also considering the limitations experienced by the youth of the GKP Cideres, the tutorial team chose the common available software to be used in fulfilling the needs of online worship services and youth school assignments. They do not need to install expensive professional video editing software to do video processing and the operating system and hardware already support the available software. The hope is that by providing this insight, participants in training activities can optimize their work by using the already available tools.

19 people from GKP Cideres were involved in the training program (5 persons as event helper that administrated and prepared all necessary equipments for webinars at the church's site, and 14 youths as training participants). 7 people from the Universitas Kristen Maranatha were involved in a committee formed consisting of a chairman of the committee (lecturer, also as the training tutor), 2 regular staffs from the Directorate of Student and Alumni Affairs, 2 assistant to the tutor, and 2 internship students in the Directorate of Student and Alumni.

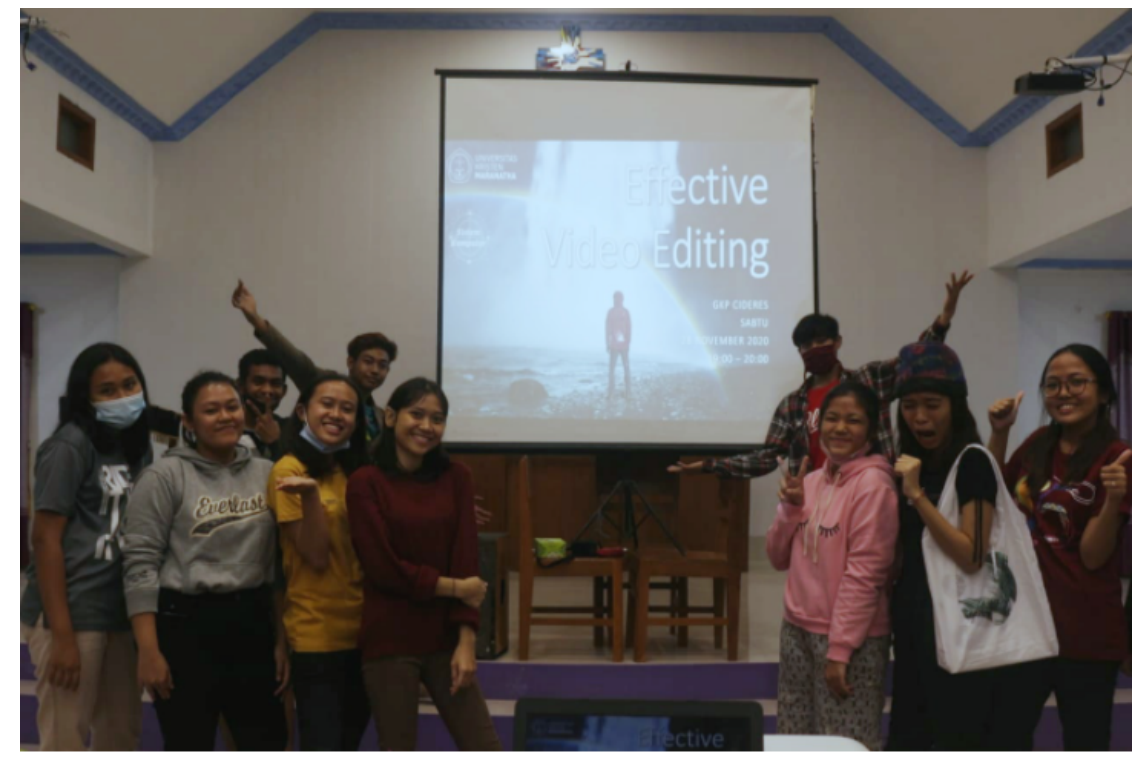

Fig. 9. Documentation of teenagers and young people of GKP Cideres 
Service Learning to Increase Utilization of X Video Editing Software Features within Limited Facilities for the Youth of 134 Gereja Kristen Pasundan Cideres

The improvement in multimedia skills in video editing resulted from the training program can be observed by comparing the initial data collected in the form of a short survey at the beginning and the end activity data collection from the training program. Before the training program, none of the training participants had ever done video editing using Microsoft Power Point. This reflected from the skills and experience of the participants at $0 \%$. At the end of training program sessions, the experience of the participants improved. $100 \%$ of the the participants were able to use the software to process video materials. All participants succeeded in participating in the whole training program and in those activities to process video materials, no significant problem was emerged. The assessment of the participant's level of experience was observed through activities of inserting video clips according to the slides provided, and producing a final video compilation output, in the use of the available softwares.

Success rate of the video processing attempt on common presentation software reached $71.43 \%$. Success rate of participants in producing videos using the same software reached $30 \%$ from the total of those successfully processing the video, or about $21,43 \%$ of all training participants.

A sufficient level of supervision in video processing training is required to anticipate errors and the effectiveness of the training material. So that questions and mistakes in training can be resolved immediately more effectively. Though the training participants skills improved, the improvement was not significant. Not all of the participants succeeded in producing a final video output. The success rate of participants in producing final video output reached 21,43\%. This happened because of:

1. Limited place for implementation (online)

2. Variety of specifications for individual laptop utilized

3. Variety of quality selection settings for final video produced (higher quality selected means need more computer performance hence more time to process in limited trining duration)

\section{Results}

Youths of the GKP Cideres were able to use necessary training materials. The results of the short exercise could be immediately put into practice because the participants brought their own laptops. Videos those had been assembled required varying processing times, regarding 
Service Learning to Increase Utilization of X Video Editing Software Features within Limited Facilities for the Youth of 135 Gereja Kristen Pasundan Cideres

to the choice of the video quality being processed and the performance specification of individual computer owned by each participant. It is hopeful that from each activities that have been carried out in the training program, the training participants can exploit new insights in making good video presentation.

After approximately 3 months after the training activities were carried out, the benefits of the training were felt to fulfill the needs of the GKP Cideres. Some of the content produced by church youth uses common available softwares those utilized in training. The effectivity of the training session provided is perceived to reach $35.71 \%$. But this low effectivity rate was probably because of the fact that not all training participant assigned to work on video processing yet since the training finished.

\section{Discussions}

Community service to the youth of the GKP Cideres has answered the needs addressed by the committee. The skills in making presentation pages can be directly converted into video. On the other hand, this activity raises other questions regarding video processing using other software. This illustrates the high level of curiosity of the participants to explore the multimedia material environment, especially in video editing and mixing.

\section{Conclusion}

In general, this form of community service to the youth of the GKP Cideres has been successfully fulfilled. The curiosity of the training participants turned out to be more than expected. So that to satisfy this spirit of the youths in the GKP Cideres, longer duration time for training sessions and a more adequate venue were needed. If it is grouped by category of multimedia skills and then ordered gradually, it is better to do video editing start from how to record the video, then how to edit the video, up to the production of the final video compilation, using the simplest and easiest to obtain softwares (such as Microsoft Power Point and Photos), commonly used alternative software (such as Filmora), to reliable software for professionals (such as Adobe Premiere Pro and Adobe After Effects).

The training to use common available softwares already built-in under Windows 10 operating system in processing videos can be generaly concluded as a success. The softwares 
Service Learning to Increase Utilization of X Video Editing Software Features within Limited Facilities for the Youth of 136 Gereja Kristen Pasundan Cideres

mentioned can be utilized as an alternative in processing videos for worship activities at the GKP Cideres and also to complete assignments from each youth's school.

The manager of the GKP Cideres in the near future will buy a computer with the ability to process videos to promote online and offline worship activities. With the new computers that have sufficient capabilities to process video, training can be expanded more widely. If possible, training will be developed in the near future on more sophisticated software. So that the results of the video presented can be more modern. a follow-up will be held 6 months from the time this activity takes place.

\section{Acknowledgements}

For a good collaboration, the author thanks the following parties, the Directorate of Student and Alumni Universitas Kristen Maranatha, youths and personnel of the GKP Cideres, the Directorate of Communication and Information Media Universitas Kristen Maranatha, assistant to the tutor Leon Karsten and Gilberth Giandy Taruna Kesumah, and also all personnel of the formed committee from the Directorate of Student and Alumni Affairs. Hopefully this training program can add insights, knowledge, relationships, and benefits to all participants and all involved committee members on duty.

\section{References}

Adobe Inc. (2013). Adobe Premiere Pro, Help and tutorials. Adobe

Ansori, M., Afandi, A., Fitriyah, R. D., \& Farisia, H. (2021). Pendekatan-Pendekatan Dalam University - Community Engagement.

Atas, R. K. (2019). Pelatihan Editing Video dan Film bagi Pegiat Lingkar Literasi di Rumah Baca Kali Atas, Cicalengka Video and Film Editing Training for Literacy Activist at Home. 3(1), 83-92.

Lambert, Joan's. (2015). Microsoft Power Point 2016 Step by Step. Microsoft Press.

Li, Ze-Nian. Drew, Mark S. Liu, Jiangchuan. (2014). Fundamentals of Multimedia, Springer. Megawati, E., Megawanti, P., \& Dinda, M. (2019). Tingkat Literasi Media Mahasiswa Pendidikan Bahasa. Simposium Nasional Ilmiah Dengan Tema Peningkatan Kualitas Publikasi Ilmiah Melalui Hasil Riset Dan Pengabdian Kepada Masyarakat, 2019 (November), 285-290. https://doi.org/10.30998/simponi.v0i0.315 
Service Learning to Increase Utilization of X Video Editing Software Features within Limited Facilities for the Youth of 137 Gereja Kristen Pasundan Cideres

Microsoft Corporation. (2016). Surface Book User Guide With Windows 10. Microsoft

Pinandia, Riza. (2019). 5 Software Editing Video Terbaik Saat ini, Academia

Sahren, S., Irianto, I., \& Akmal, A. (2020). Membangun Kreatifitas Pemuda Milenial Melalui Konten Video Multimedia Komputer. Jurdimas (Jurnal Pengabdian Kepada Masyarakat) Royal, 3(1), 75-80. https://doi.org/10.33330/jurdimas.v3i1.497 